\title{
An Empirical Study of the Relationship between Money Supply and House Price: Taking Anhui Province as an Example
}

\author{
Wang Ying Xin \\ Business School of Nanjing Normal University \\ Nanjing, Jiangsu \\ China
}

\begin{abstract}
Since the housing reform in 1998, the real estate market in various regions of China has begun to flourish, and a series of problems caused by the rise of house prices have become the focus of attention of the state and the government. The impact of money supply growth on the real estate market should not be underestimated. In order to understand the relationship between money supply and house prices, this paper takes Anhui Province as an example to study the influence of the change of generalized money supply (M2) on real estate prices. The results show that the money supply has a positive effect on the housing prices, and there is a long-term equilibrium relationship between the two. According to the results, the paper puts forward some policy suggestions on how to rationally regulate the money supply of real estate industry and perfect the bank credit policy.
\end{abstract}

Keywords: money supply, M2, house price, co-integration test

\section{Introduction}

Since the reform of the housing system in China in 1998, the welfare housing distribution policyhas been cancelled, and the rise and fall of housing prices in our country began to be free, which has promoted the booming development of the real estate industry and become an important pillar industry of the economic development of our country.

Since 2003, the real estate industry has overheated in China's first-tier cities. In order to control this phenomenon, Chinese government introduced the corresponding measures in 2005 and 2006, such as "eight articles of the country" and "six articles of the country."(Wen, X. C, et al., 2015).But in 2007, the annual rate of increase in house prices still reached $10 \%$. The outbreak of the subprime mortgage crisis in the United States in 2008 led to a global economic downturn (Petrosky-Nadeau, N, et al., 2016). In order to stimulate economic development, Chinese adopted relatively loose fiscal and monetary policies. Housing prices are also rising. In 2009, macroscopical indicators in good condition, the rise of land prices to play an intrinsic role in this circumstance, and the rise of land prices will inevitably bring the growth of housing prices, China's real estate industry is still rapid development. Until the end of 2013, The rate of increase in first-tier cities exceeded 15\%, and in Shanghai it was as high as $30 \%$.By the beginning of 2016, the real estate market was in short supply, first-tier cities appear a rush to buy houses, and house prices in central provinces were growing rapidly (Shi, Q, et al., 2017), so the corresponding restrictions imposed by provincial capitals such as Hefei. In March 2017, The National Bureau of Statistics released the latest data, commercial housing sales area year-on-year growth of $19.5 \%$.

The booming real estate market is already the pillar industry of our country's national name economy, and the contribution to our country's GDP is about 5\% every year since the reform. Although the real estate industry promotes the development of the national economy, it also brings inevitable social contradictions while pulling GDP(Yu, D, et al., 2017). The increasing demand for housing is in contradiction with purchasing power and housing supply. There are a lot of speculative opportunities in the real estate industry, housing prices continue to soar, the existence of real estate bubbles affect the overall macroeconomic development, breeding a lot of potential dangers.

\section{Background}

\subsection{Analysis of the current situation of the money supply.}


In total terms, the balance of money and quasi-money supply (M2) reached 15, 500, 666.7 billion yuan in 2016, with a year-on-year growth of $11.2 \%$ (Zhang, S, et al., 2017). For the same period, the balance of money (M1) was 486557.2.4 billion yuan, a year-on-year growth of 21.4\%. As the chart(fig1) shows that the Cash in circulation (M0) balance was 68303.87 billion yuan and a year-on-year growth by that segment of $8.1 \%$.Overall, the three-level money supply increase, the year-on-year growth rate of change was in line with the trend.

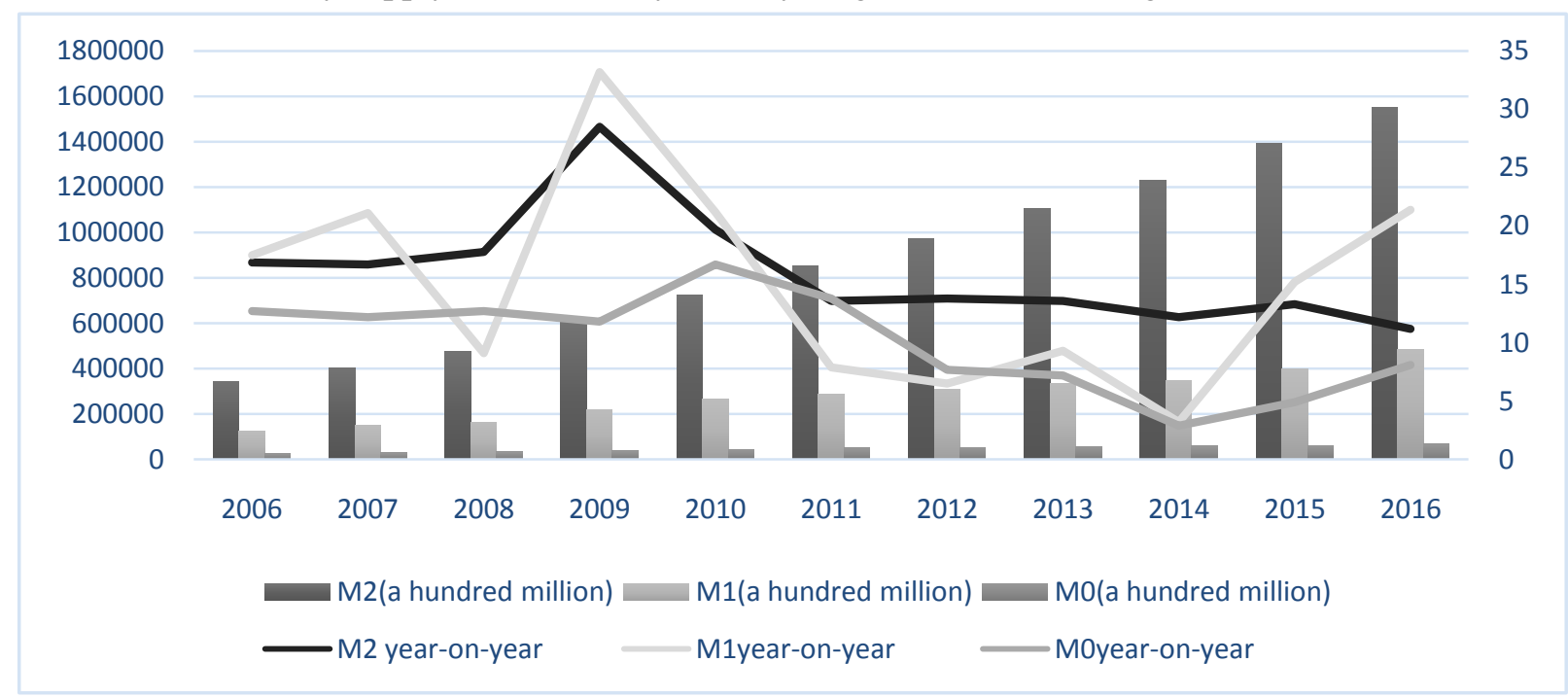

\section{Source: State Statistics Bureau}

Fig1.Change in M0,M1,M2

From the indicators' perspective, financial deepening indicators are usually expressed by M2/GDP(Kiganda, E, et al., 2017). This ratio reflects the proportion that currency takes as a medium in economic activities, reflects the financial depth of the economy, and measures the degree of monetization of a country's economy(Koivu,T, et al., 2012). The greater the value, the deeper the degree of financialization of the country's economy. According to the changing trend of M2/GDP, it was basically stable before 2008. After the subprime mortgage crisis, the central bank adopted a more relaxed monetary policy to stimulate economic recovery, resulting in a relatively large increase in the ratio in 2009. Meanwhile, the gap between the growth of M2 and GDP began to widen. The growth rate of M2 exceeded the growth rate of GDP. This index has been maintained between 1.5 and 2 in the last decade.

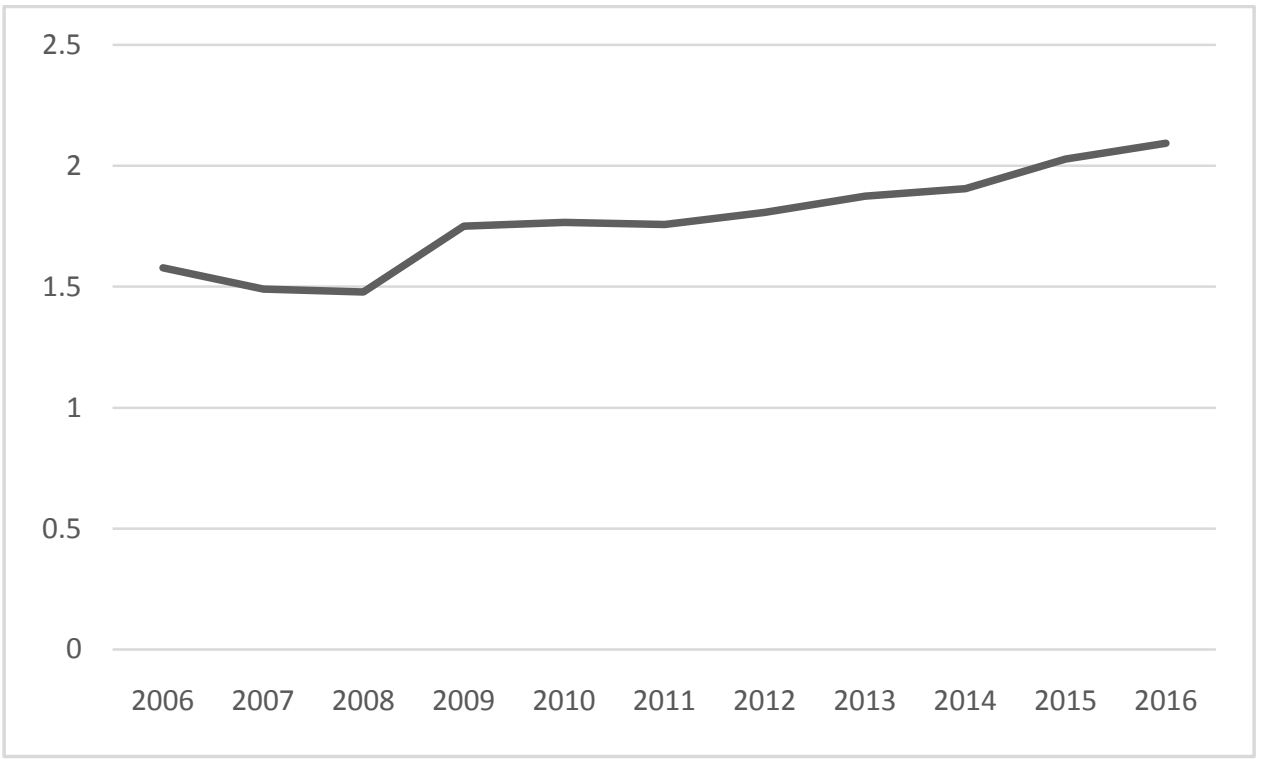

Source: State Statistics Bureau

Fig2.Changes in M2/GDP 


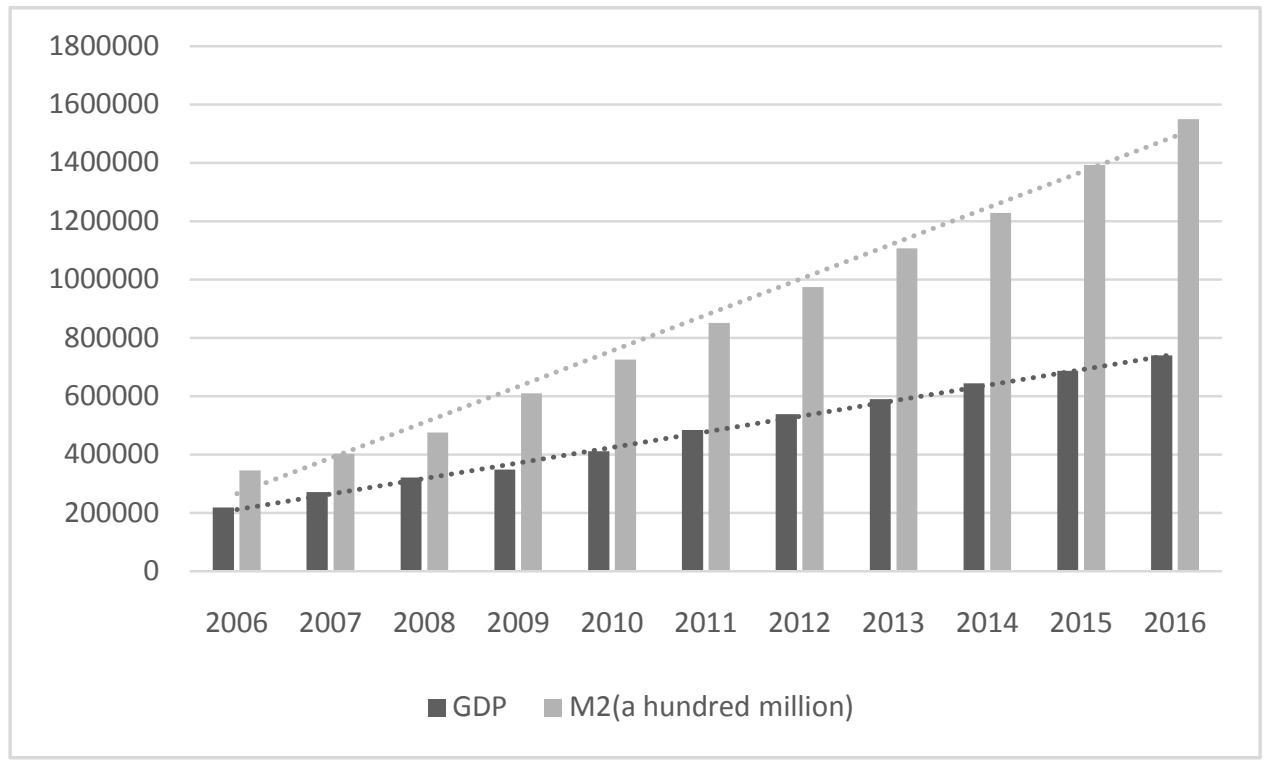

Source: State Statistics Bureau

Fig3.Growth in GDP and M2

The monetary structure specifically refers to the currency circulation structure, so it also reflects the change of monetary liquidity(Griffin, J. M, et al., 2016). The main reference indicators are M0/M2 and M1 / M2. When the excessive issuance of money causes inflation, the monetary liquidity increases, and the reference index value rises. On the contrary, the change of indicators facilitates the central bank to analyze the changes in the overall economic environment. From the specific data and trends of the two indicators in the figure, we can see that the proportion of M0 and M1 in M2, which has strong liquidity, has shown a downward trend, indicating that with the development of society, people are no longer blindly pursuing the circulation function of money. Instead, we should turn our attention to other functions of money. Under the condition of keeping the price level stable, we shall ensure that the development of the economy and realize the target of monetary policy (Towbin, P, et al., 2016).

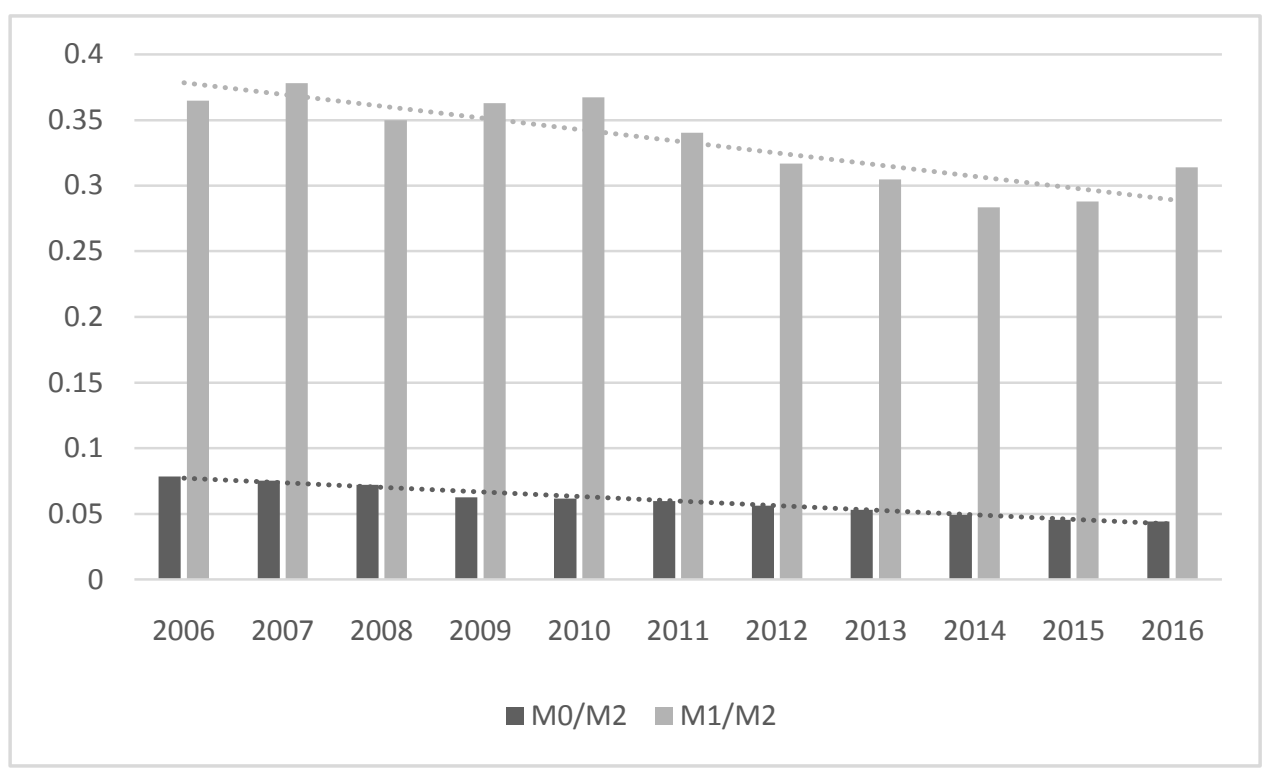

Fig4.Changes in monetary structure indicators

Source: State Statistics Bureau

\subsection{Analysis of the current situation of housing prices in Anhui Province}

In 2016, housing prices in Anhui Province have reached 5924 yuan per square meter. As a central inland province, the real estate market in Anhui Province started late and its housing price is at a relatively low level compared with first-tier cities' housing prices which have exceeded 10,000 yuan. 
However, due to the particularity of geographical location and the role of the booming real estate market in the surrounding first-tier cities, the housing prices in Anhui Province are broadly in line with the development process of other central regions of China, such as Shanxi, Henan, Hubei, Jiangxi and Hunan's, the six neighboring provinces, the average price is higher (Shi, P, et al., 2012). The increase in Anhui's housing price is large, as shown in the chart. There is a 1000 yuan per square meter gap between the average selling price of Hunan, Shanxi, and Henan and that of Anhui Province. The housing prices in Jiangxi Province also falls behind Anhui Province in the early stage, and in the latter period it is basically equal to that of Anhui Province; the average selling price in Hubei Province is basically the same as that of Anhui Province. From the data we can see that,as located in the central region, Anhui's real estate sales average price is in the leading position.

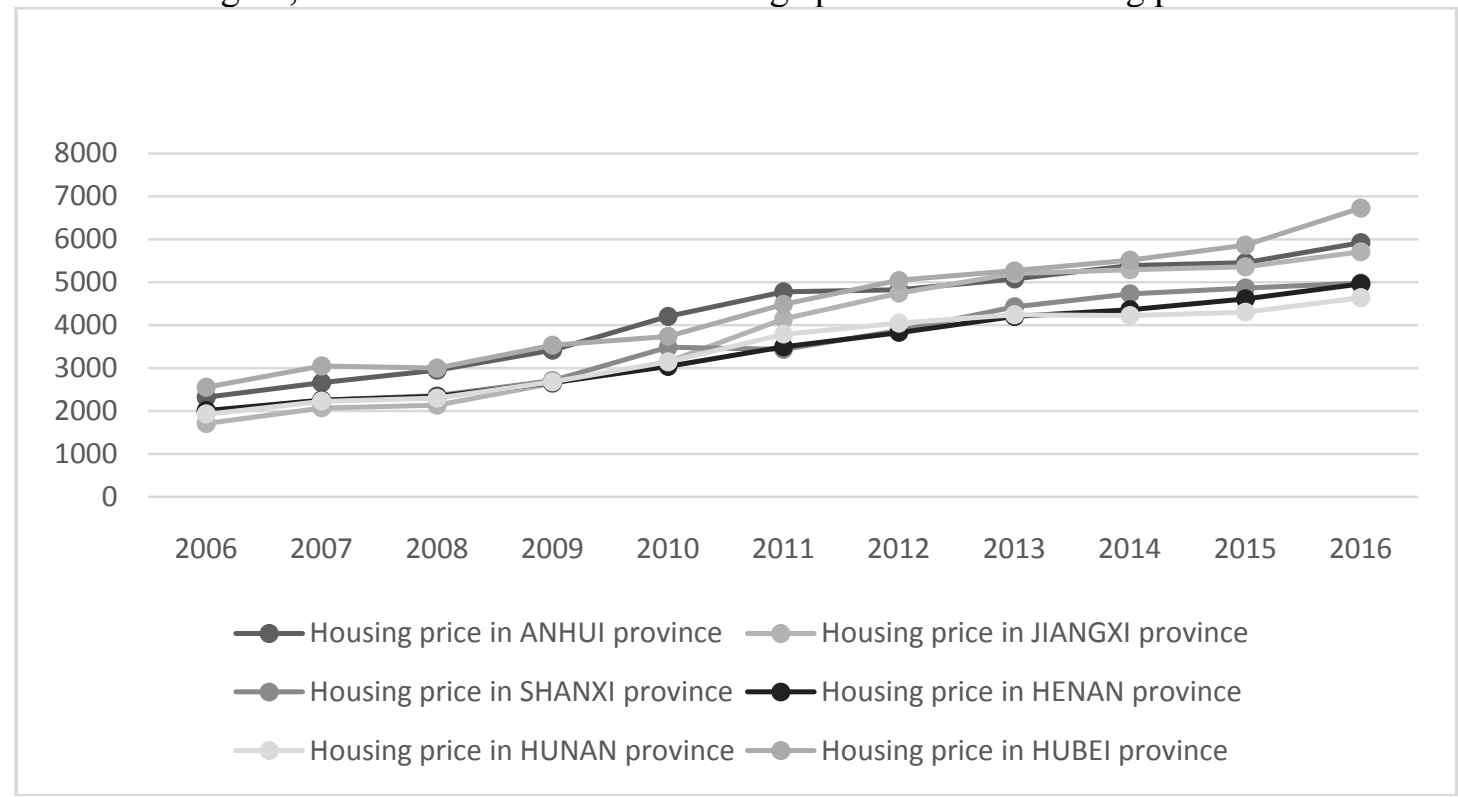

\section{Source: Statistical Yearbook}

Fig5.A comparison of house prices in central China

\subsection{Trend Analysis of money supply (M2) and House Price}

In this paper, we select M2 and Anhui housing price to analyze the trend of the increase of M2 and house price. In view of the year-on-year growth rate and set 2006 as the base year, the rate of house price growth has lagged behind the change of the money supply, and the growth rate of M2 has remained above $10 \%$, while the growth rate of house prices has fluctuated twice in 2008 and 2010, respectively. As shown in the diagram. In general, M2 is in line with the trend of house prices in Anhui Province, but the growth rate of house prices lags behind that of M2.

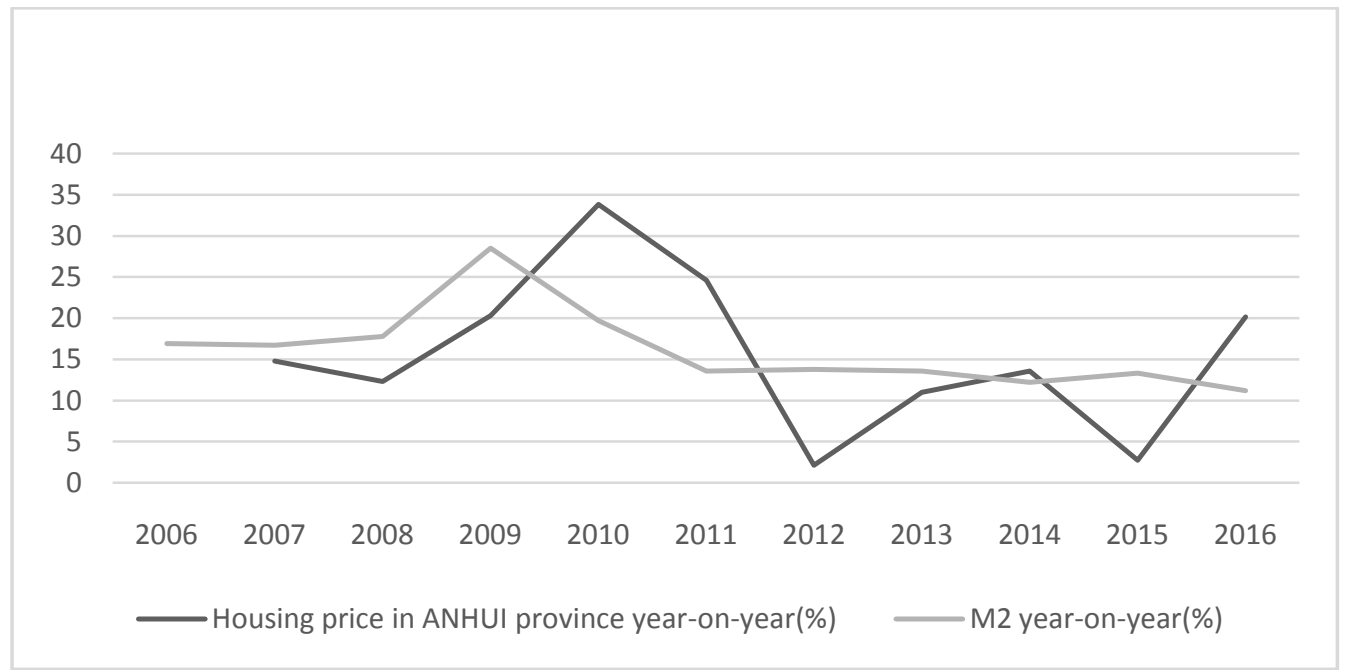

Fig6.M2 and Housing price in ANHUI province(year-on-year)

\section{Source:State Statistics Bureau andStatistical Yearbook}




\subsection{The main influence ways of money supply on House Price}

Because of the particularity of housing as a commodity, the credit function of financial institutions is needed to provide sufficient funds to the real estate industry. The operation of the real estate industry is closely related to bank credit activities. To put it simply, the way that bank credit affects house prices is to affect the liquidity of money funds, real interest rates, and residents' expectations firstly, thereby affecting developers' ability to develop and raise funds, as well as buyers' consumerism and demands. All these have led to housing prices fluctuations. Rising prices mean higher commodity values, and businesses and individuals who hold more valuable collateral are more likely to obtain bank loans, as shown in the following figure. Under the synergistic effect, the liquidity of the credit market is stable, the loan issuance is orderly, and the house price will continue to rise.

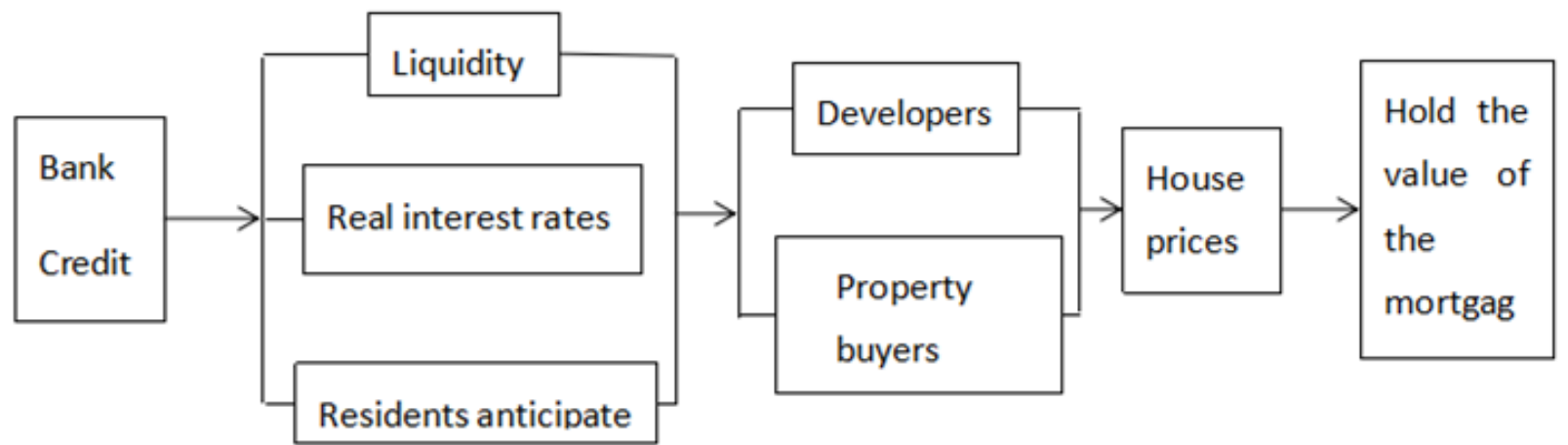

Fig7.The main influence ways of money supply on House Price

\section{Data Consolidation}

\subsection{Selection of variables and data sources}

Money supply has three levels: M0, M1, and M2.M2 is a quasi-money added to M1, which can represent not only the currency with real purchasing power but also the currency with potential purchasing power. It reflects the change in money demand in economic society and reflects the relationship between money supply and commodity price. It is more reasonable as an economic variable. Therefore, the data selection of the money supply in this paper is more closely related to the real economy M2, hereinafter referred to as M2. At the same time, we selected the provincial capital city of Anhui Province and its monthly housing price data as a representative, recorded as P. In the experiment, 78 groups of data were selected from June 2010 to November 2016 to carry out an empirical study on the effect of the change of money supply on house prices. Housing prices are obtained from the official website of the China Institute of Indexes, while monthly money supply data are selected from the Oriental Wealth data Center. Because M2 is affected by many factors, the sequence composed of economic variables belongs to a time series. In order to avoid heteroscedasticity, a relatively stable sequence can be obtained by taking a logarithm of the obtained data. For processed data defined as LOGP and LOGM2.

\subsection{The process and result of empirical analysis}

\subsubsection{Correlation test}

Table1.Correlation coefficient table

\begin{tabular}{lll}
\hline & LOGP & LOGM2 \\
\hline LOGP & 1.000000 & 0.699605 \\
LOGM2 & 0.699605 & 1.000000 \\
\hline
\end{tabular}

According to the correlation coefficient diagram of Correlation coefficient table, the correlation coefficient between M2 and $\mathrm{P}$ is 0.699605 . It shows that the rise of M2 promotes the rise of $\mathrm{P}$.

\subsubsection{Unit Root Test}

Because of the possibility of uneven stability in macroeconomic variables, we should use the unit root test to judge whether the time series is stationary or not. The statistical value of the stationary sequence is constant and changing time will not affect it. The ADF test is used in the unit root test, and the obtained data are shown in the following table. 
Table 2. ADF test results

\begin{tabular}{lllll}
\hline variable & $(\mathrm{c}, \mathrm{t}, \mathrm{n})$ & ADF value & $5 \%$ critical value & Conclusion \\
\hline LOGP & $(\mathrm{c}, 0,1)$ & 1.4927 & -3.4688 & Non-stationary \\
LOGP & $(\mathrm{c}, 0,2)$ & -0.2107 & -3.4696 & Non-stationary \\
dLOGP & $(\mathrm{c}, 0,1)$ & -3.6889 & -3.4696 & stationary** \\
LOGM2 & $(\mathrm{c}, 0,1)$ & -1.8422 & -2.8996 & Non-stationary \\
LOGM2 & $(\mathrm{c}, 0,2)$ & -1.9126 & -2.9001 & Non-stationary \\
dLOGM2 & $(\mathrm{c}, 0,1)$ & -7.5171 & -2.9001 & stationary** \\
\hline
\end{tabular}

Notes: 1.(C) $t(n)$ denotes the type of test, where $c$ denotes the constant term, $t$ denotes the time trend term and $n$ represents the lag order;2. ${ }^{* * *} *$ means significant at a significant level of $5 \%$

From the test results in the table, the ADF test results of the original series of selected time variables are all greater than the critical value of 5\% significant level, and means it is a non-stationary time series. However, the ADF test values of the time series obtained after the first-order difference are all smaller than the critical value, which rejects the original assumption that there is no unit root, and the newly formed first-order difference sequence belongs to the stationary sequence. It is suggested that there may be a long-term equilibrium relationship between $\mathrm{M} 2$ and $\mathrm{P}$, which suggests $\mathrm{CO}$-integration.

\subsubsection{Co-integration test}

Because LOGP and LOGM2 are one-order monolithic sequences. The possible long-term equilibrium relationship between them shows that the internal mechanism of equilibrium will not be changed under macro-economy, that means when the variable is affected and the gap between the long-term equilibrium point widens, the equilibrium mechanism will be adjusted in the next period to return to equilibrium again. This equilibrium relationship means that there is no intrinsic mechanism to destroy the equilibrium in the economic system. If the variable deviates from its long-term equilibrium point after a certain period of disturbance, the equilibrium mechanism will be adjusted in the next phase to make it return to the equilibrium state. The LOGP and LOGM2 are cointegrated and corrected by the Engle-Granger two-step test method.

\section{a. Using OLS Model to obtain a regression equation}

Table3a.regression equation

\begin{tabular}{|c|c|c|c|c|}
\hline Variable & Coefficient & Std Error & t-Statistic & Prob. \\
\hline C & 2737721 & 0.461689 & 5.929793 & 0.0000 \\
\hline LOGM2 & 0.443030 & 0033300 & 13.30414 & 0.0000 \\
\hline R-squared & 0.699605 & \multicolumn{2}{|c|}{ Mean dependent var } & 8879140 \\
\hline Adjusted R-squared & 0.695652 & \multicolumn{2}{|c|}{ S D dependent var } & 0.130378 \\
\hline $\mathrm{S}$ E of regression & 0.071926 & \multicolumn{2}{|c|}{ Akaike înfo criterion } & -2.401042 \\
\hline Sum squared resid & 0.393178 & \multicolumn{2}{|c|}{ Schwarz criterion } & -2.340613 \\
\hline Log likelihood & 95.64063 & \multicolumn{2}{|c|}{ F-statistic } & 177.0000 \\
\hline Durbin-Watson stat & 0.045509 & \multicolumn{2}{|c|}{ Prob(F-statistic) } & 0.000000 \\
\hline
\end{tabular}

From the value of regression model, we can see that the t statistics of the constant term and independent variable have passed the significance test. The fitting degree of one variable regression equation is general and the constant term and independent variable coefficient are both positive. It shows that $\mathrm{M} 2$ change and $\mathrm{P}$ change do show a positive correlation. $1 \%$ change in $\mathrm{M} 2$ can lead to $0.443 \%$ change in $\mathrm{P}$. The equation is obtained as follow:

LOGP $=0.443 \mathrm{dLOGM} 2+2.738$

(13.30) (5.92)

$\mathrm{R}^{2}=0.699 \quad \mathrm{~F}=177$ 
The numbers in parentheses are the corresponding $\mathrm{t}$ statistical value and $\mathrm{F}$ statistical value which indicate that the linear relation of the resultant equation is significant. The $\mathrm{R}^{2}=0.69$ indicates that the fitting degree is general.

\section{b. Residual ADF test}

Let the residuals of (1) be the RESID01, residuals equation:

RESID01=LOGP-0.443LOGM2-2.738

A new residual sequence is obtained, and the residual sequence is tested by ADF. The results are shown in the following table.

Table3b.Residual ADF test results

\begin{tabular}{lcllc}
\hline variable & $(\mathrm{c}, \mathrm{t}, \mathrm{n})$ & ADF value & $\begin{array}{l}5 \% \\
\text { value }\end{array}$ & critical \\
\hline RESID01 & $(\mathrm{c} .0,1)$ & -3.687654 & -3.4696 & stationary** \\
\hline
\end{tabular}

The results show that the residual error is a stationary sequence, then it is proved that there is a co-integration relationship between $\mathrm{P}$ and M2 after logarithm, that is, there is a long-term equilibrium relationship between them. The coefficient of LOGM2 is 0.443 , that is, when M2 increases by $1, \mathrm{P}$ will rise by 0.553 .

\section{c. Error correction model}

Engle and Granger have put forward the Grange representation theorem, that if the two variables are cointegrated, there is a long-term equilibrium relationship between them, but the short term is not in equilibrium. This kind of short-term disequilibrium relationship can be expressed by an error modification model. Because of the co-integration relationship between LOGP and LOGM2, the error correction model is established. The residual RESID01 sequence is modified, the error correction model is established, the first order difference is obtained for LOGP and LOGM2, and the model results are obtained:

DLOGP $=0.975 *$ DLOGP(-1)-0.673*RESID01(-1) + 0.025*DLOGM2

$$
\mathrm{R}^{2}=0.89 \quad(3.107) \quad(-2.002)
$$

It can be seen from (3) that the coefficient of error correction is negative, which is in accord with the reverse correction mechanism. The coefficient representing M2 is positive, that means $\mathrm{P}$ is also positive. It indicates that the change of house price in the short term is revised to $0.557 \%$ of the deviation of house price in the long-term equilibrium.

\section{d. Granger causality tests}

The above tests prove that there is a long-term co-integration relationship between M2 and P, and this stable relation of long-term equilibrium also indicates that there may be a causal relationship between the two variables. In economics, Granger causality test is generally used to test whether the change of one variable is the cause of the change of another variable. Two to five periods of lag data were selected in this test. The results of the

\begin{tabular}{|c|c|c|c|}
\hline \multicolumn{2}{|c|}{ lag period hypothesis } & \multirow{2}{*}{$\begin{array}{l}\begin{array}{r}\text { sample } \\
\text { capacity }\end{array} \\
76\end{array}$} & \multirow{2}{*}{$\begin{array}{l}\mathrm{P} \quad \text { Conclusion } \\
0.00015 \text { refuse }^{* *}\end{array}$} \\
\hline 2 & LOGP does not Granger Cause LOGM2 & & \\
\hline & LOGM2 does not Granger Cause L0GP & & 0.00167 refuse ${ }^{* *}$ \\
\hline & DLOGP does not Granger Cause DLOGM2 & 75 & 0.00216 refuse $* *$ \\
\hline & DLOGM2 does not Granger Cause DLOGP & & 0.00873 refuse $* *$ \\
\hline \multirow[t]{4}{*}{3} & LOGP does not Granger Cause LOGM2 & 75 & 0.00142 refuse ${ }^{* *}$ \\
\hline & LOGM2 does not Granger Cause LOGP & & 0.00898 refuse $^{* *}$ \\
\hline & DLOGP does not Granger Cause DLOGM2 & 74 & 0.00765 refuse $* *$ \\
\hline & DLOGM2 does not Granger Cause DLOGP & & 0.00541 refuse $* *$ \\
\hline \multirow[t]{4}{*}{4} & LOGP does not Granger Cause LOGM2 & 74 & 0.00443 refuse $* *$ \\
\hline & LOGM2 does not Granger Cause LOGP & & 0.00532 refuse $^{* *}$ \\
\hline & DLOGP does not Granger Cause DLOGM2 & 73 & 0.00953 refuse $* *$ \\
\hline & DLOGM2 does not Granger Cause DLOGP & & 0.00447 refuse $* *$ \\
\hline \multirow[t]{4}{*}{5} & LOGP does not Granger Cause LOGM2 & 73 & 0.45869 accept** \\
\hline & LOGM2 does not Granger Cause LOGP & & 0.00612 refuse $* *$ \\
\hline & DLOGP does not Granger Cause DLOGM2 & 72 & 0.85602 accept** \\
\hline & DLOGM2 does not Granger Cause DLOGP & & 0.05408 refuse $* *$ \\
\hline
\end{tabular}
experiment are as follows. Table4.Granger causality tests results 
The test results show that at the significant level of 5\%, the first order differential DLOGP and DLOGM2 of LOGP and LOGM2 are also Granger's causes at the time of delay of 2 or 4 stages, and the first-order differential DLOGP and DLOGM2 of LOGP and LOGM2 are also Granger's cause. That is to say, the increase in M2 will lead to the increase in $\mathrm{P}$ and the increase in $\mathrm{P}$ will also lead to the increase in $\mathrm{M} 2$, which indicates that the sensitivity between variables is very high. At the time of delay of 5 periods, only LOGM2 is the Granger reason of LOGP and the first-order differential DLOGP, and DLOGM2 of LOGM2 are the same, which indicates that the increase in M2 will lead to the increase in $\mathrm{P}$, but the increase in $\mathrm{P}$ will not lead to the increase in M2. It shows that when the lag number is larger, the house price is more sensitive to the change of M2. Otherwise, it is slightly weaker.

\section{Discussions and Conclusions}

Based on the study of the relationship between M2 and housing prices in Anhui Province, it is concluded that the change of M2 has a significant effect on the real estate prices in Anhui Province. Because the development degree of Anhui Province is lagging behind that of the developed coastal areas, there are fewer investment channels with higher popularity at present. For the ordinary residents, it is the most important choice to invest in the increasingly developing real estate market by using bank credit. As a result of a large amount of money flowing into the real estate market, demand for housing is exuberant. However, Anhui Province is located in the inland, considering the natural environment and government project development, the available land resources are limited, and a large amount of money inflow leads to a sharp imbalance between supply and demand in the short term, resulting in a real estate bubble. In the short term, house prices fluctuate greatly, that means the broad money supply has a significant positive effect on house prices in Anhui Province.

Based on the empirical conclusion, we can know that there is a long-term equilibrium relationship between the housing prices in Anhui Province and the broad money supply, so in the long run, the surplus funds in the real estate market of Anhui Province are conducive to attract more investment opportunities. In the long-term, to maintain a positive feedback mechanism to maintain the stability of the real estate market. As a representative area in central China, the real estate industry is one of the pillar industries in Anhui Province, and the change of housing prices is of great significance to other regions.

Therefore, it is necessary to fully consider the status quo of Anhui Province's development, combining the current situation of Anhui's real estate market and choosing the proper monetary policy to regulate the money supply. Besides, the transformation of different monetary policies should be slow and steady. Combining price tools with quantitative tools to regulate and control the rational distribution of money supply, control the inflow of money into the real estate market. Strengthening the monitoring of the ways of inflow and outflow, preventing the money supply from being too fast, and lead to the flood of liquidity. To ensure that the currency flow in the real estate market remains within a normal range of fluctuations. It will neither retain surplus speculative opportunities nor cause house prices to fluctuate sharply.

Credit activities in the real estate market have been frequent in recent years. For non-line areas such as Anhui Province, financial risks are hidden in both domestic and foreign markets. For commercial banks, the largest proportion of loans is housing loans. When house prices suddenly fall, the value of mortgage houses falls, and banks face great loan risks.In order to prevent banks from excessive lending to the real estate industry in pursuit of their own interests, and to create financial risks, first of all, they should strengthen the examination of the credit qualifications of lenders, and secondly, they should cooperate with the government's purchase restriction policy to ensure that credit activity doesn't cause the real estate market to fluctuate violently.

When making loans, we should carry out differential loans, comprehensively investigate the credit of buyers, establish a dynamic loan period, and judge the use of property purchased by consumers. At the same time, in order to balance the demand in the real estate market, most comfortable housing should be given a loose repayment period and set up different loan interest rate preferential policy.

Finally, as the main regulator of the financial environment in Anhui Province, the Anhui Branch of the people's Bank of China should also actively cooperate with the central bank's monetary policy. Banking regulators should strengthen the supervision of commercial banks' real estate loan business and make the fluctuation of house price in a reasonable and healthy level. In a word, regulators need to play a macro-control role in the real estate market, it should promote the real estate industry and financial industry mutual penetration, and jointly promote the development of the national economy. 


\section{References}

Griffin, J. M., \&Maturana, G. (2016).Did dubious mortgage origination practices distort house prices?. Ssrn Electronic Journal, 29, págs. 1671-1708.

Wen, X. C., \& He, L. Y. (2015). Housing demand or money supply? a new keynesian dynamic stochastic general equilibrium model on china's housing market fluctuations. Physica A Statistical Mechanics \& Its Applications, 432, 257-268.

Towbin, P., \& Weber, S. (2016). Price expectations and the u.s. housing boom. Social Science Electronic Publishing, 15(182), 1.

Koivu, T. (2012).Monetary policy, asset prices and consumption in China, Economic System, 36(2), 307-325.

Petrosky-Nadeau, N. (2016). Financial fritions, the housing market, and unemployment.Journal of Economic Theory, 164, 101-135.

Kiganda, E. (2017). Relationship between inflation and money supply in kenya. Journal of Social Economics, 2,64-83.

Zhang, S., \& He, M. (2017). An Empirical Study on the Influence of Price scissors of M1-M2 Growth on House Prices. International Conference on Economics, Management Engineering and Education Technology, 1, 26-31.

Yu, D., Qin, J., Fang, D., Wang, B., \& Chuting, K. (2017). Correlation analysis among real estate development investment,gdp and house price in china. Journal of Liaoning Shihua University, 37(1), 70-74.

Shi, Q., \& Fan, F. (2017).Effect of money supply, bank credit to housing price fluctuation. China Real Estate, 36, 23-30.

Shi, P., \&Jin, Y. U. (2012).Re-test of the relationship among housing price,land price and money supply-with shaanxi province as an example. Journal of Northwest A \& F University, 12(6), 125-129. 